\title{
Surgical Practice in Girls with Congenital Adrenal Hyperplasia: An International Registry Study
}

\author{
Doris Hebenstreit $^{\mathrm{a}} \quad$ S. Faisal Ahmed ${ }^{\mathrm{b}}$ Nils Krone ${ }^{\mathrm{c}}$ Christoph Krall $^{\mathrm{d}} \quad$ Jillian Bryce $^{\mathrm{b}}$ \\ Sabah Alvi ${ }^{\text {e }}$ Rita Ortolano ${ }^{f}$ Mario Lima ${ }^{9}$ Niels Birkebaek ${ }^{\text {h }}$ Walter Bonfigi,j Hedi Claahsen \\ van der Grinten ${ }^{k}$ Eduardo Correa Costal Sukran Poyrazoglum ${ }^{m}$ Liat de Vries ${ }^{n}$ Christa \\ E. Flück ${ }^{\circ}$ Tulay Guran $^{p}$ Fuat Bugrul ${ }^{p}$ Ayla Güven ${ }^{q}$ Violeta lotovar ${ }^{r}$ Birgit Koehler $^{s}$ \\ Jennyver-Tabea Schröder ${ }^{s}$ Daniel Konrad ${ }^{t}$ Evelien Gevers ${ }^{u, v}$ Ruth Krone ${ }^{w}$
}

Tatjana Milenkovic ${ }^{x}$ Ana Vieites ${ }^{y}$ Richard Ross ${ }^{c}$ Rieko Tadokoro Cuccaro ${ }^{z}$ leuan Hughes ${ }^{z}$ Carlo Acerini ${ }^{z}$ Alexander Springer ${ }^{\mathrm{A}}$

aDepartment of Urology, Hanusch Krankenhaus, Vienna, Austria; ' ${ }^{\circ}$ Developmental Endocrinology Research Group, Royal Hospital for Children, University of Glasgow, Glasgow, UK; ${ }^{C}$ University of Sheffield, Sheffield, UK; ${ }^{d}$ Center for Medical Statistics, Informatics, and Intelligent Systems, Section for Medical Statistics, Medical University of Vienna, Vienna, Austria; 'Paediatric Endocrinology, Leeds Children's Hospital, Leeds Teaching Hospitals NHS Trust, Leeds, UK; ' Department of Medical and Surgical Sciences, Pediatric Unit, S.Orsola-Malpighi University Hospital, Bologna, Italy; ${ }^{9}$ Department of Medical and Surgical Sciences, Pediatric Surgery Unit, S.Orsola-Malpighi University Hospital, Bologna, Italy; hDepartment of Paediatrics, Aarhus University Hospital, Aarhus, Denmark; 'Department of Pediatrics TU Munich, Munich, Germany; ${ }^{j}$ Klinikum Wels-Grieskirchen, Wels-Grieskirchen, Austria; ${ }^{\text {kDepartment of }}$ Paediatric Endocrinology, Radboud University Amalia Childers Hospital Medical Centre, Nijmegen, The Netherlands; IPediatric Surgery Service, Hospital de Clínicas de Porto Alegre, UFRGS, Porto Alegre, Brazil; mIstanbul Faculty of Medicine, Department of Paediatrics, Paediatric Endocrinology Unit, Istanbul University, Istanbul, Turkey; ${ }^{\text {nThe }}$ Jesse and Sara Lea Shafer Institute of Endocrinology and Diabetes, Schneider Tel Aviv Children's Medical Center of Israel, Sackler Faculty of Medicine, Tel Aviv University, Tel Aviv, Israel; ${ }^{\circ}$ Pediatric Endocrinology, Diabetology and Metabolism, Department of Pediatrics and Department of BioMedical Research, Bern University Hospital Inselspital,

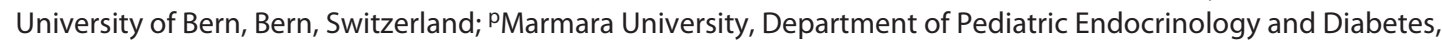
Pendik, Istanbul, Turkey; ${ }^{9} S a g l i k$ Bilimleri University Medical Faculty, Zeynep Kamil Women and Children Hospital, Pediatric Endocrinology Clinic, Istanbul, Turkey; 'Department of Paediatrics, Medical University-Varna, UMHAT "Sv. Marina", Varna, Bulgaria; 'Klinik für Pädiatrische Endokrinologie und Diabetologie, Charité - Universitätsmedizin Berlin, Corporate Member of Freie Universität Berlin, Humboldt-Universität zu Berlin, Berlin, Germany; ${ }^{\text {tDivision }}$ of Paediatric Endocrinology and Diabetology, University Children's Hospital, Zurich, Switzerland; "Department of Paediatric Endocrinology, Barts Health NHS Trust, Royal London Hospital, London, UK; ${ }^{\vee}$ Centre for Endocrinology, William Harvey Research Institute, Queen Mary University London, London, UK; 'Birmingham Women's \& Children's Hospital, Department for Endocrinology \& Diabetes, Birmingham, UK; ${ }^{\times}$Department of Endocrinology, Mother and Child Health Care Institute of Serbia "Dr Vukan Čupić", Belgrade, Serbia; '⿳Centro de Investigaciones Endocrinológicas, División de Endocrinología, Hospital de Niños Ricardo Gutiérrez, Buenos Aires, Argentina;

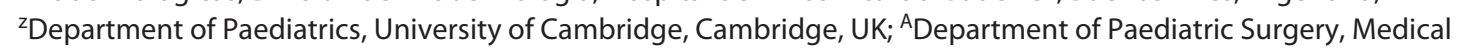
University Vienna, Vienna, Austria

(C) 2021 The Author(s)

Published by S. Karger AG, Basel

This is an Open Access article licensed under the Creative Commons Attribution-NonCommercial-4.0 International License (CC BY-NC) (http://www.karger.com/Services/OpenAccessLicense), applicable to the online version of the article only. Usage and distribution for commercial purposes requires written permission.
Correspondence to:

Alexander Springer, alexander.springer@ meduniwien.ac.at 


\section{Keywords}

Congenital adrenal hyperplasia - Disorders of sexual

development $\cdot$ Intersex $\cdot$ Surgery

\section{Abstract}

In this article international trends in surgical practice in girls with congenital adrenal hyperplasia $(\mathrm{CAH})$ are evaluated. All cases that had been classified in the I-CAH/I-DSD registry as 46,XX CAH and who were born prior to 2017 were identified. Centers were approached to obtain information on surgical decision making. Of the 330 included participants, 208 (63.0\%) presented within the first month of life, and 326 (98.8\%) cases were assigned female. Genital surgery had been performed in 250 (75.8\%). A total of 64.3, 89.2, and $96.8 \%$ of cases residing in Europe, South America and Asia, respectively, had at least one surgery. In a logistic regression model for the probability of surgery before the second birthday (early surgery) over time an increase of probability for early vaginal surgery could be identified, but not for clitoral surgery or both surgeries combined. Genitoplasty in girls with $\mathrm{CAH}$ remains controversial. This large international study provides a snapshot of current practice and reveals geographical and temporal differences. Fewer surgeries were reported for Europe, and there seems to be a significant trend towards aiming for vaginal surgery within the first 2 years of life.

(C) 2021 The Author(s).

Published by S. Karger AG, Basel

\section{Introduction}

Congenital adrenal hyperplasia $(\mathrm{CAH})$ is the most common diagnosis in infants with virilization, 46,XX DSD. The incidence of classic virilising $\mathrm{CAH}$ is about $1: 15,000$ in most populations in the world [Speiser et al., $2010]$. More than $95 \%$ of cases are caused by 21 -hydroxylase deficiency, which is characterized by defective glucocorticoid synthesis in all patients and mineralocorticoid synthesis in some. Precursors to cortisol and aldosterone accumulate and are shunted toward androgen production, starting in fetal life. The prenatal excess of androgens results in virilization of 46,XX infants [Speiser et al., 2010]. Most girls with CAH present with atypical genitalia [Merke and Auchus, 2020], and although they have traditionally been treated by early sex-conforming surgery, this approach has increasingly been debated with clinicians/parents opting not to undertake any surgery before the age of consent [Kolesinska et al., 2014; Wolffen- buttel and Crouch, 2014; Bougneres et al., 2017]. Studies performed on large data sets from international cohorts such as the International DSD registry (www.i-dsd.org) have been successfully used in different scientific projects [Ahmed et al., 2014]. With the recent extension of this registry platform to include patients with CAH (www.icah.org), the current study was designed to evaluate changes over time in CAH-related surgical practice. In particular, we wanted to find out whether there was a change over time in the rate of early feminizing genitoplasty. We divided our dataset of patients into 2 equally distributed groups (1996-2006, 2007-2017). By chance, the distribution coincidenced with the Chicago consensus of 2006, which was followed by many important consensus and position papers concerning care of patients with DSD (Office of the High Commissioner for Human Rights, United Nations for Intersex Awareness, https:// www.ohchr.org/EN/Issues/LGBTI/Pages/IntersexPeople.aspx, 2016; Parliamentary Assembly of the Council of Europe, Resolution 2191, https://assembly.coe.int/nw/ x m l / X R e f / X r e f - X M L 2 H T M L - e n . asp?fileid=24232\&lang=en) [Méndez, 2013; Deutsche Gesellschaft für Urologie (DGU) e.V., 2016; Mouriquand et al., 2016; Cools et al., 2018; Krege et al., 2019].

\section{Material and Methods}

The I-DSD and the I-CAH registries are international registries, approved by the National Research Ethics Service of the United Kingdom, for storage of pseudo-anonymized data. Data are collected as part of routine clinical practice following informed consent of the parents or patients [Kourime et al., 2017]. All cases that had been registered until 2018 as 46,XX disorder of androgen excess due to $\mathrm{CAH}$ and who were born prior to 2017 were included in this study. We identified 555 patients from 41 centers, who were born between 1953 and 2016. These centers were approached to obtain additional information on factors that influenced the option of performing surgery, timing of surgery, type of surgery, and the length of the follow-up period (the questionnaire for the centers is available in online suppl. Table 1 ; for online suppl. material, see www.karger.com/doi/10.1159/517055).

The centers were provided a 6-month period to respond, and during this period $21(51.2 \%)$ centers completed and returned the questionnaires on a total of 334 of 555 eligible cases $(60.2 \%)$. Of the 334 completed questionnaires, 330 (98.8\%) from 12 countries in Europe (15 centers, $n=199)$, Asia and Turkey ( 4 centers, $n=$ 94), and South America ( 2 centers, $n=97$ ) were suitable for analysis. In this study, we included only patients born between January 1995 and December 2015 who had their first presentation between January 1996 and December 2016 before their first birthday $(n=$ 184) (Fig. 1). Out of the 184 patients included, 104 patients (56\%) were registered in European centers, 59 patients (32\%) were registered in Asian centers, and 21 patients (11\%) were registered in South American centers. Prader score at first presentation was 
Fig. 1. Inclusion/exclusion flow diagram of

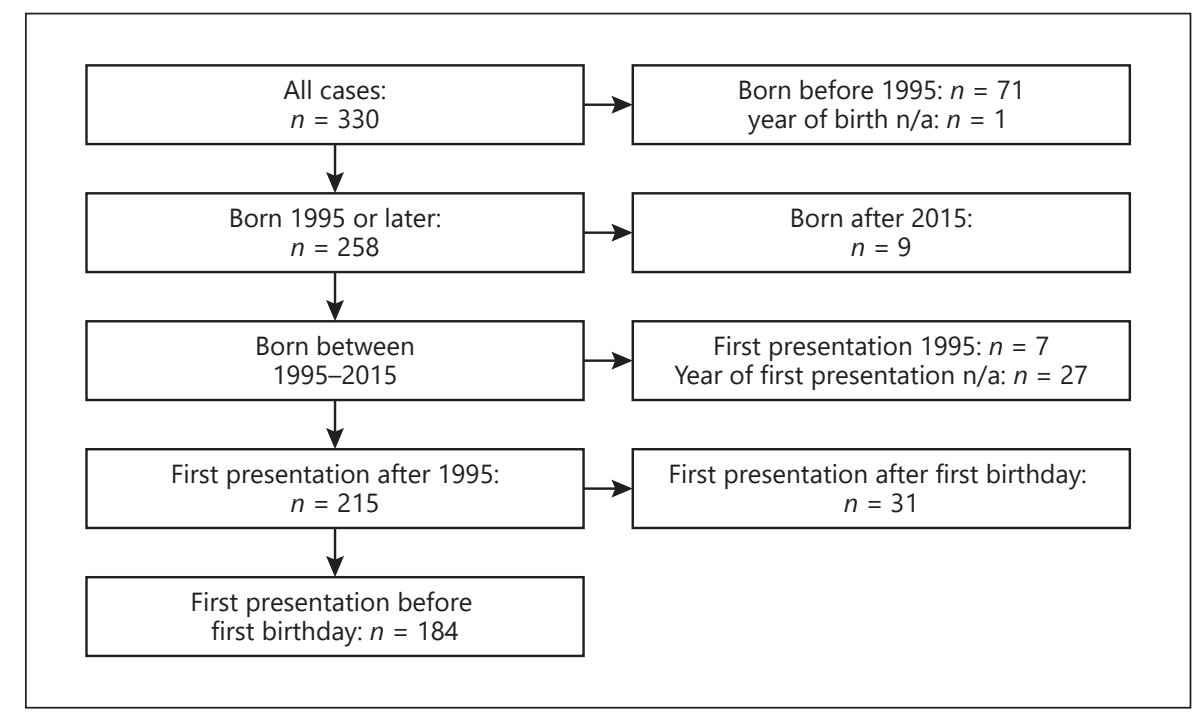
the sample.

available for 122 patients (66\%), external masculinization score (EMS) [Ahmed et al., 2000] at first assessment was available for 67 patients (36\%). A total of 90 patients (49\%) had their first presentation before or in 2006, 94 patients (51\%) presented in 2007 or later.

\section{Statistical Analysis}

Early surgery was defined as surgery before 24 months of life. For univariate analysis, a logistic regression of the probability of early surgery for patients presenting before their first birthday was performed. Patients for which no information about early surgery was available were considered as missing values. Differences in proportions of early surgery before and after 2006 were analyzed by a Pearson's $\chi^{2}$ test, and correlation between early surgery and Prader score and EMS were investigated by Wilcoxon tests. In a multiple logistic regression model we included the year of first presentation with an interaction term with the cut off at 2006, and the Prader score dichotomized as up to 2 and $>2$. In a sensitivity analysis, the calculations were repeated in a nonlinear mixed model with the random effect intercept per center. All statistical calculations were performed with $\mathrm{R}$ versions 3.5.1 and 3.6.3.

\section{Results}

\section{Clinical Characteristics}

Of the 184 cases, 160 patients (87\%) presented within the first month of life, 15 patients (8\%) presented between month 1 and end of month 3 , and 9 patients (5\%) presented between month 4 and their first birthday. A total of 172 patients (93\%) had 21-hydroxylase deficiency, 6 (3\%) had $11 \beta$-hydroxylase deficiency, and 6 patients (3\%) had other forms of CAH. At birth, 183 (99\%) cases were assigned as female, and 1 case was not assigned to any sex.
At latest assessment, all cases had a female sex assignment. Prader score was available in 122 patients $(66 \%)$ with a median of 4 (IQR: 3-4, range: 0-5; EMS at first assessment was entered for 67 patients (36\%) with a median of 7 [IQR: 7-9, range: 4-10]).

\section{Surgery}

Altogether, 184 patients were born between January 1996 and December 2016 and had their first presentation within the first year of life: 94 patients $(51 \%)$ presented between 1996 and 2006, 90 patients (49\%) presented in 2007 or later. In sum, 51 patients (28\%) did not have surgery before their second birthday (no early surgery), 65 patients $(35 \%)$ had at least 1 operation before their second birthday. For 68 patients (37\%) this information was not available: for 3 patients it was unclear whether they had surgery, 6 patients without surgery had their last followup before their second birthday, and for 59 patients with surgery the date of surgery remained unknown. Of those 65 patients with at least 1 operation before their second birthday, 54 patients (83\%) had vaginal as well as clitoral surgery, 7 patients (10\%) had clitoral but no vaginal surgery, 2 patients (3\%) had vaginal but no clitoral surgery, and 2 patients (3\%) had clitoral surgery with no information about vaginal surgery. Of the 54 cases who had both operations, in $3(6 \%)$ clitoral surgery was performed first, in 48 patients $(89 \%)$ both surgeries were performed simultaneously, and for 3 patients this information was not available. Age at last follow-up was equally distributed between patients with early surgery (median 10, range $0-20$ ), patients without early surgery (median 10, range 
Table 1. Probability of having early surgery did not change over time $(p=0.59)$

\begin{tabular}{lll}
\hline & $\begin{array}{l}\text { Patients (\%) presenting in } \\
\text { 2006 or before }\end{array}$ & $\begin{array}{l}\text { Patients (\%) presenting } \\
\text { in 2007 or later }\end{array}$ \\
\hline No early surgery & $24(27)$ & $27(29)$ \\
\hline At least one early surgery & $35(39)$ & $30(32)$ \\
\hline Information not available & $\begin{array}{l}31(34) \\
\text { unknown date: 28 } \\
\text { lost to follow-up: 2 } \\
\text { unclear if surgery: 1 }\end{array}$ & $\begin{array}{l}\text { unknown date: } 31 \\
\text { lost to follow-up: } 4 \\
\text { unclear if surgery: } 2\end{array}$ \\
\hline
\end{tabular}

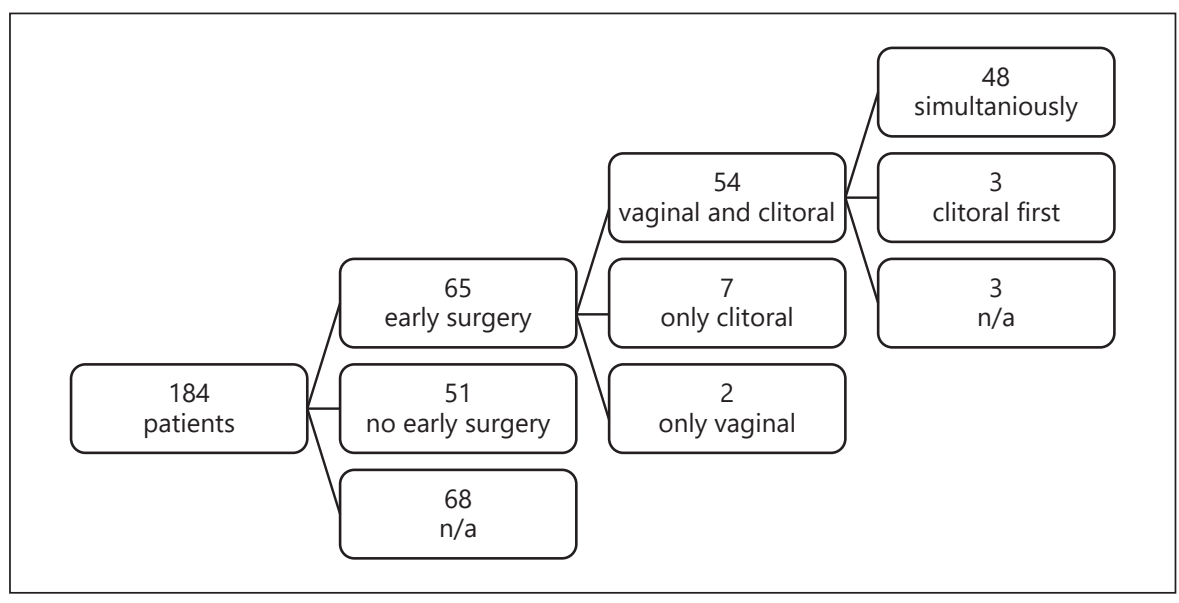

Fig. 2. Estimated trend for proportion of early surgeries over time. test identified no difference in proportions before and after 2006. Also, when geographical regions were analyzed separately, proportions of girls with early surgery before and after the statement did not differ substantially (Europe: 18 out of 49 [36.7\%] before 2006 vs. 15 out of 57 [27.3\%] after 2006; South America: 5 out of 11 [45.5\%] before vs. 5 out of 10 [50\%] after 2006; Asia: 12 out of 30 [40\%] before vs. 10 out of 29 [34.5\%] after). Due to the geographic bias of this study no further analysis was performed.

\section{Clinical Features Associated with the Likelihood of Surgery}

Prader score was available for 34 patients without early surgery (median: 3, range: 0-5, IQR: $2-4$ ), 45 patients with early surgery (median: 4 , range: $2-5$, IQR: $3-4$ ), and 43 patients with unknown early surgery status (median: 4, range: $0-5$, IQR: 3-4). A Wilcoxon rank sum test identified differences between Prader scores of patients with and without early surgery $(p=0.002)$. EMS was available for 67 patients. Median EMS reported for those who did not have early surgery $(n=17)$ was 7 (range: $4-10$, IQR: $6-8)$, median EMS for those who had surgery $(n=28)$ was 
7 (range: 4-10, IQR: 7-7), median EMS for patients with unknown early surgery status $(n=22)$ was 7 (range: $4-10$, IQR: 7-9). A Wilcoxon rank sum test identified no differences between first EMS of patients with and without surgery $(p=0.55)$. First EMS was available for 67 girls and missing for 117 girls, with median 7 and range 4-10. Prader Score was available for 122 girls and missing for 62 girls, with median 4 and range $0-5$. For 51 patients (27.7\%) neither Prader nor EMS score were available.

Analysis of data regarding the influence of patient, parent, clinician, society, religion, and media for the decision-making process was not possible due to heterogeneity and incompleteness.

\section{Multiple Logistic Regression}

Logistic regression was performed for the proportion of early surgery regarding the year of first presentation. No significant change of the proportion of early surgeries over the year of first presentation was identified $(\mathrm{OR}=$ $0.99,95 \% \mathrm{CI}=[0.92,1.07], p=0.780)$. Inclusion of an interaction between time and the cut off at 2006 did not identify a change in trend of the proportion of early surgery after $2006(\mathrm{OR}=1.23,95 \% \mathrm{CI}=[0.94,1.62], p=$ $0.135)$. For those patients with known Prader score, in a logistic regression model with covariates year of first presentation and dichotomized Prader score, no trend could be identified (OR: 1.05, 95\% CI $=[1.00,1.11], p=0.067$ ), but a higher proportion of early surgeries was associated with a Prader score $>2$ (OR: 6.54, 95\% CI = [1.84, 31.11], $p=0.007)$. In a sensitivity analysis, nonlinear mixed models with the random effect center were analyzed which gave the same results (data not shown).

\section{Discussion}

Despite the widespread controversy in the medical community, media, and general population, there is a significant lack of reliable or prospective data on genital surgery in CAH. Therefore, the subject of this study was to evaluate the current surgical practice and changes over time in children with CAH within the I-CAH and I-DSD registries. Data from over 184 girls with $\mathrm{CAH}$ were accessed and analyzed to investigate trends in early surgery. To our knowledge this is the largest international study of a contemporary approach to surgery in these patients.

Apart from one patient, where information on sex assignment was not available, all patients were raised as girls, and around $35 \%$ had at least one reported genital surgery before their second birthday. When early surgery

Surgical Practice in Girls with Congenital

Adrenal Hyperplasia was performed, the majority of all patients had complete urogenital reconstruction in one step. When a staged approach was followed, clitoroplasty preceded vaginoplasty. Postponing surgery is a concept that is not reflected by our data: no change in the proportion of early surgeries over time could be identified, and there was no change in the probability of having early surgery over time. The current recommendation is to perform surgery only in cases of severe virilization (Prader III, IV, and V) [Hughes et al., 2006]. Wolffenbuttel and Crouch [2014] recommend one stage surgery for severely virilized genitalia and deferring surgery in milder cases whenever possible. Different expert opinion papers recommend early single-stage genital repair for girls with severe virilization, performed by experienced surgeons [Speiser et al., 2010; Yankovic et al., 2013]. On the other hand, non-surgical treatment or delayed surgery is considered to be an option for patients with a phenotypical genital variation. Recently, a study suggested deferring genital surgery in girls with 21 -hydroxylase deficiency into adolescence as a feasible option. However, none of these girls have reached puberty so far [Bougneres et al., 2017]. On the contrary, there is information on individuals with complete masculinization, 46,XX karyotype, and CAH raised as boys, with some displaying gender dysphoria and some not. The social support seams to play a crucial role in the development of their sexual identity. de Jesus et al. [2019] reported a higher percentage of gender dysphoria in individuals with 46, XX CAH raised as males compared to those raised as females, 9 and $18.4 \%$ respectively, but with a confounding factor considering late diagnosis in most male-raised individuals [Lee et al., 2010; Khattab et al., 2017]. A consensus statement recently published stresses the importance of informed consent and a holistic, multidisciplinary care for the patients, and postponing the genital surgery until the individual is old enough to be actively involved in the decision whenever possible was advised [Cools et al., 2018].

Genital surgery has become the most controversial part of DSD management. Reconstructive surgery of the genitalia, historically thought to be in the individual's best interest by normalizing the phenotype and defining an acceptable gender role, has been appraised extremely critical over the years until in 2012 the UN Report of the Special Rapporteur on torture and other cruel, inhuman, or degrading treatment or punishment underlines the importance of non-discriminating, no forced gender-confirming surgery and specialized holistic care [Méndez, 2013]. Finally, in 2017 the Council of Europe published the resolution 2191 called "Promoting the human rights of and 
eliminating discrimination against intersex people resolution" (available at https://assembly.coe.int/nw/xml/XRef/ Xref-XML2HTML-en.asp?fileid=24232\&lang=en) emphasizing the right of physical integrity in children or infants who are unable to give consent and whose gender identity is unknown. This practice has largely been adopted in DSD management. However, there is controversy whether this strict policy is also applicable to individuals with $\mathrm{CAH}$ raised as females: on one hand there is a tendency to exclude CAH from the umbrella term DSD (pushed by affected individuals themselves) and on the other hand the majority of individuals with $\mathrm{CAH}$ raised as females and their families still support early surgery [Deutsche Gesellschaft für Urologie (DGU) e.V., 2016; Szymanski et al., 2020; Shalaby et al., 2021].

In a recent German interdisciplinary consensus paper, adolescents and young women with $\mathrm{CAH}$ from a group of about 600 patients with CAH declared agreement with surgery performed early in childhood, and they do not consider early correction of urogenital sinus as cosmetic procedures [Krege et al., 2019]. Jesus [2018] also supports these findings. In a study performed in 2015 in the USA, only $219 / 573(38.2 \%)$ received feminizing genitoplasty over a 4-year period of surveillance. Median patient age was $<1$ year at first procedure in the combined genitoplasty cohort and $74 \%$ of combined procedures were performed at $<2$ years [Sturm et al., 2015]. In other US centers management and timing of surgery differs significantly. In a study from 2010 it was shown that feminizing genitoplasty procedures were performed in $46 \%$ of girls and $60 \%$ of all procedures were performed by the age of 2 years [DaJusta et al., 2010].

Ethics of allowing parents to consent for genital surgeries that could permanently impair the genital sensation of the child are difficult [Schoer et al., 2018]. Due to the poor quality of data, our survey was not able to analyze trends whether media, society, religion, and others influence the decision-making process significantly. However, the role of cultural, religious, and social attitudes in the decision-making process as well as patients' and parents' opinion will require a more detailed investigation [Joint LWPES/ESPE CAH Working Group, 2002; Mouriquand et al., 2016].

\section{Conclusion}

In summary, our study shows no change of practice over time in feminizing genitoplasty in girls with 46,XX CAH. Global disease registries such as the I-DSD and I-
$\mathrm{CAH}$ registries represent an important resource for longterm monitoring of surgical practice and its outcomes. Inclusion of patient-reported outcome parameters in the I-DSD/I-CAH registries will be of tremendous importance in order to obtain feedback from individuals with DSD directly and not only through caring DSD teams.

\section{Acknowledgements}

During working on this project, we were saddened to learn of the death of our colleagues and co-investigators Dr. Birgit Köhler, Department of Pediatrics, Charité University Medicine, Berlin/ Germany and Dr. Carlo L. Acerini, Department of Paediatrics, University of Cambridge, UK. We value their contributions to this article, the field of pediatric endocrinology, and the I-CAH and IDSD network. We dedicate this paper to their memory.

\section{Statement of Ethics}

Patient and/or parental consent was obtained prior to registration of cases in the I-DSD Registry. The I-DSD Registry is approved by the National Research Ethics Service of the UK.

\section{Conflict of Interest Statement}

The authors have no conflicts of interest to declare.

\section{Funding Sources}

The I-CAH Registry was developed using support from an unrestricted education grant from Diurnal Ltd, Medical Research Council (partnership award to SFA ref G1100236, the Seventh European Union Framework Program (201444) and the Research Unit of the European Society for Paediatric Endocrinology.

\section{Author Contributions}

Conception and design of the work: D.H., F.S.A., N.K., A.S. Data acquisition: D.H., F.S.A., N.K., C.K., J.B., S.A., R.O., M.L., N.B., W.B., H.C., E.C.C., S.P., L.V., C.E.F., T.G., F.B., A.G., V.I., B.K., J.-T.S., D.K., E.G., R.K., T.M., A.V., R.R., R.T.C., I.H., C.A. Data analysis and interpretation: D.H., F.S.A., N.K., C.K., A.S. Drafting the work or revising it critically for important intellectual content: D.H., F.S.A., N.K., C.K., A.S. Final approval of the version to be published and agreement to be accountable for all aspects of the work in ensuring that questions related to the accuracy or integrity of any part of the work are appropriately investigated and resolved: D.H., F.S.A., N.K., C.K., J.B., S.A., R.O., M.L., N.B., W.B., H.C., E.C.C., S.P., L.V., C.E.F., T.G., F.B., A.G., V.I., B.K., J.-T.S., D.K., E.G., R.K., T.M., A.V., R., R.T.C., I.H., C.A., A.S. 


\section{References}

Ahmed SF, Bryce J, Hiort O. International networks for supporting research and clinical care in the field of disorders of sex development. Endocr Dev. 2014;27:284-92.

Ahmed SF, Khwaja O, Hughes IA. The role of a clinical score in the assessment of ambiguous genitalia. BJU Int. 2000;85(1):120-4.

Bougneres P, Bouvattier C, Cartigny M, Michala L. Deferring surgical treatment of ambiguous genitalia into adolescence in girls with 21-hydroxylase deficiency: a feasibility study. Int J Pediatr Endocrinol. 2017;2017:3.

Cools M, Nordenström A, Robeva R, Hall J, Westerveld P, Flück C, et al. Caring for individuals with a difference of sex development (DSD): a Consensus Statement. Nat Rev Endocrinol. 2018;14:415-29.

DaJusta D, Xu L, Baker L. 535 Frequency of feminizing genitoplasty for congenital adrenal hyperplasia with the geographical distribution of surgeries in the US. J Urol. 2010;183(4S): e211.

de Jesus LE, Costa EC, Dekermacher S. Gender dysphoria and XX congenital adrenal hyperplasia: how frequent is it? Is male-sex rearing a good idea? J Pediatr Surg. 20198;54:2421-7.

Deutsche Gesellschaft für Urologie (DGU) e.V. DGfKDeV. Deutsche Gesellschaft für Kinderendokrinologie und -diabetologie (DGKED) e.V.: S2k AWMF Guidelines Disorders of Sexual Development (in German: S2k-Leitlinie Varianten der Geschlechtsentwicklung). Berlin; 2016.

Hughes IA, Houk C, Ahmed SF, Lee PA. Consensus statement on management of intersex disorders. J Pediatr Urol. 2006;2:148-62.

Jesus LE. Feminizing genitoplasties: Where are we now? J Pediatr Urol. 2018;14:407-15.
Joint LWPES/ESPE CAH Working Group. Consensus statement on 21-hydroxylase deficiency from the Lawson Wilkins Pediatric Endocrine Society and the European Society for Paediatric Endocrinology. J Clin Endocrinol Metab. 2002;87:4048-53.

Khattab A, Yau M, Qamar A, Gangishetti P, Barhen A, Al-Malki S, et al. Long term outcomes in 46,XX adult patients with congenital adrenal hyperplasia reared as males. J Steroid Biochem Mol Biol. 2017;165:12-7.

Kolesinska Z, Ahmed SF, Niedziela M, Bryce J, Molinska-Glura M, Rodie M, et al. Changes over time in sex assignment for disorders of sex development. Pediatrics. 2014;134:e7105.

Kourime M, Bryce J, Jiang J, Nixon R, Rodie M, Ahmed SF. An assessment of the quality of the I-DSD and the I-CAH registries - international registries for rare conditions affecting sex development. Orphanet J Rare Dis. 2017;12: 56.

Krege S, Eckoldt F, Richter-Unruh A, Köhler B, Leuschner I, Mentzel HJ, et al. Variations of sex development: The first German interdisciplinary consensus paper. J Pediatr Urol. 2019;15:114-23.

Lee PA, Houk CP, Husmann DA. Should male gender assignment be considered in the markedly virilized patient With 46,XX and congenital adrenal hyperplasia? J Urol. 2010; 184:1786-92.

Méndez J. Report of the special rapporteur on torture and other cruel, inhuman or degrading treatment or punishment. Human Rights Council. United Nations Digital Library; 2013.

Merke DP, Auchus RJ. Congenital adrenal hyperplasia due to 21-hydroxylase deficiency. N Engl J Med. 2020;383:1248-61.
Mouriquand PD, Gorduza DB, Gay CL, MeyerBahlburg HF, Baker L, Baskin LS, et al. Surgery in disorders of sex development (DSD) with a gender issue: If (why), when, and how? J Pediatr Urol. 2016;12:139-49.

Schoer MB, Nguyen PN, Merritt DF, Wesevich VG, Hollander AS. The role of patient advocacy and the declining rate of clitoroplasty in 46,XX patients with congenital adrenal hyperplasia. Clin Pediatr (Phila). 2018;57:1664-71.

Shalaby M, Chandran H, Elford S, Kirk J, McCarthy L. Recommendations of patients and families of girls with 46,XX congenital adrenal hyperplasia in the United Kingdom regarding the timing of surgery. Pediatr Surg Int. 2021; 37:137-43

Speiser PW, Azziz R, Baskin LS, Ghizzoni L, Hensle TW, Merke DP, et al. Congenital adrenal hyperplasia due to steroid 21-hydroxylase deficiency: an Endocrine Society clinical practice guideline. J Clin Endocrinol Metab. 2010;95:4133-60.

Sturm RM, Durbin-Johnson B, Kurzrock EA. Congenital adrenal hyperplasia: current surgical management at academic medical centers in the United States. J Urol. 2015;193: 1796-801.

Szymanski KM, Rink RC, Whittam B, Hensel DJ. Majority of females with a life-long experience of $\mathrm{CAH}$ and parents do not consider females with CAH to be intersex. J Pediatr Urol. 2021;17:210.e1-210.e9.

Wolffenbuttel KP, Crouch NS. Timing of feminising surgery in disorders of sex development. Endocr Dev. 2014;27:210-21.

Yankovic F, Cherian A, Steven L, Mathur A, Cuckow P. Current practice in feminizing surgery for congenital adrenal hyperplasia. A specialist survey. J Pediatr Urol. 2013;9:1103-7. 